\title{
Cost-Effectiveness of Early Treatment with Originator Biologics or Their Biosimilars After Methotrexate Failure in Patients with Established Rheumatoid Arthritis
}

Dipen Patel · Ahmed Shelbaya · Raymond Cheung · Jyoti Aggarwal •

Sang Hee Park · Javier Coindreau

Received: April 9, 2019 / Published online: May 30, 2019

(C) The Author(s) 2019
TNFis or addition of biosimilar TNFis to MTX monotherapy at 6 months).

Results: Early intervention with an originator biologic TNFi at 6 months was associated with increases in total lifetime costs of $£ 1692$ and utilities of 0.10 quality-adjusted life-years (QALYs) per patient compared with standard intervention at 12 months, resulting in an incremental costeffectiveness ratio (ICER) of $£ 17,335 /$ QALY. Early intervention with a biosimilar TNFi increased costs by $£ 70$ and utilities by 0.10 QALYs per patient and was associated with an ICER of $£ 713$ / QALY.

Conclusion: Switching from MTX monotherapy to combination therapy with either an originator biologic or biosimilar TNFis at 6 months after csDMARD failure in patients with RA was cost-effective at a threshold of $£ 30,000 / \mathrm{QALY}$.

Funding: Pfizer Inc.

Keywords: Biologic; Biosimilar; Cost-effectiveness; Early intervention; Methotrexate; Rheumatology; Rheumatoid arthritis

\section{INTRODUCTION}

Pharmerit International, Bethesda, MD, USA

e-mail: dpatel@pharmerit.com

D. Patel · A. Shelbaya · R. Cheung · J. Coindreau

Pfizer Inc, New York, NY, USA

A. Shelbaya

Columbia University Mailman School of Public

Health, New York, NY, USA
Rheumatoid arthritis (RA) is a chronic, systemic immune-inflammatory disease that frequently results in joint pain and stiffness, structural joint damage, and functional disability [1]. The estimated global prevalence of RA is $0.3-1.0 \%$ 
[2], and the disease is associated with a substantial health and economic burden [3]. RA symptoms are often inadequately controlled, adversely affecting patients' social functioning, ability to work, and overall well-being [4]. The total annual cost of RA to society has been estimated as approximately $€ 45$ billion in Europe and $€ 42$ billion in the USA [5]. The introduction of innovative biologic therapies such as tumor necrosis factor inhibitors (TNFis) for the treatment of RA represents a major medical advance, as these agents have been shown to be highly effective in improving clinical symptoms and physical function, and slowing radiographic progression in patients with moderate to severe disease [6]. Although TNFis have considerably increased the likelihood of remission or low disease activity in patients with RA, the cost of these biologic agents can be prohibitive, leading to restricted use even as second-line therapy in some countries [7].

Over the past decade, biosimilar versions of these agents have been developed and subsequently approved by regulatory agencies, including the European Medicines Agency (EMA) [8] and US Food and Drug Administration (FDA) [9], for the treatment of RA and other autoimmune diseases. Unlike generics, biosimilars are required to undergo extensive investigation to obtain regulatory approval. Based on global guidelines from the World Health Organization, which are reflected in standards adopted by regional/national authorities such as the EMA and FDA, biosimilar authorization requires data from stringent comparability exercises, including quality, non-clinical, and clinical studies [10]. To demonstrate biosimilarity, differences between biosimilar and originator biologics cannot be greater than differences expected between different batches of the same originator biologic, and can have no impact on the clinical performance of the biosimilar. Biosimilar TNFis are expected to expand patient access to highly effective treatment because of their lower cost. Their introduction has improved patients' and clinicians' therapeutic choices, and has stimulated competition with originator biologics, which may result in cost savings for healthcare systems around the world [11].
Because longer duration of disease activity in individuals with RA may increase the risk of joint damage and functional disability, early control of inflammation can be effective in limiting structural deterioration and functional impairment [12-15]. Increasing evidence suggests that early aggressive treatment of RA provides greater benefits than treatment started later in the disease course [16]. These findings have resulted in a shift favoring earlier biologic use in patients with RA and high disease activity despite conventional synthetic disease-modifying antirheumatic drug (csDMARD) therapy. Although biologic therapies are often considered cost-effective in specific RA populations [17], the impact of earlier initiation of such therapy on the cost burden of RA has not been well studied. In addition, despite the increased interest in regulatory approval for biosimilar versions of originator biologics indicated for the treatment of inflammatory conditions, including RA, little research is available on the costeffectiveness of biosimilars. The objective of this current analysis was to estimate the cost-effectiveness of early treatment with originator biologic or biosimilar TNFis in patients with established RA who had an inadequate response to csDMARD monotherapy from a United Kingdom (UK) societal perspective.

\section{METHODS}

\section{Model Structure}

A Microsoft Excel ${ }^{\circledR}$-based Markov model was developed to estimate lifetime treatment costs, direct medical and non-medical costs, indirect costs (i.e., work productivity loss), and utilities for cohorts of patients with established RA. Characteristics of patients in the starting population were derived from the RA-BEAM trial [18], a 52-week randomized controlled trial comparing the efficacy and safety of methotrexate (MTX) monotherapy, an originator biologic TNFi, and a non-TNFi biologic in patients with moderately to severely active RA who had an inadequate response to MTX therapy administered for at least 12 weeks. Based on the trial, the starting population in the model 
was $69 \%$ female, with an average age of 53 years.

A simplified care paradigm was assumed for the model: patients received csDMARDs, originator biologic/biosimilar TNFis (combined with csDMARDs), and originator biologic non-TNFis in a stepwise fashion based on response status (cycle length, 3 months) (Fig. 1). Using disease activity score in 28 joints (DAS28) criteria, response status was defined as remission (DAS28 $<2.6$ ), low disease activity (DAS28 $\geq 2.6$ to $<3.2$ ), and high disease activity (DAS28 $\geq 3.2$ ).

In the standard intervention group, patients were initiated on MTX monotherapy and those with an inadequate response (i.e., high disease activity) after 12 months were switched to the next treatment, MTX plus an originator biologic. In the early intervention group, patients were evaluated after 6 months of MTX monotherapy for addition of an originator biologic (early biologic intervention) or biosimilar (early biosimilar intervention). The response status of patients who remained on MTX monotherapy was assessed annually to determine whether an originator biologic or biosimilar TNFi should be added, based on high disease activity. After initiation of TNFi therapy, patients who continued to remain in high disease activity were switched to non-TNFi biologic therapy at a specified annual rate. Other patients receiving TNFis who responded to the treatment remained in the same disease activity state until death, unless they relapsed from remission to low disease activity. The model assumed that the only difference between originator biologic and biosimilar TNFis was the treatment cost; all other parameters (e.g., efficacy, discontinuation/switch rate, utilities) remained equal. The model used in this analysis was based on previously conducted studies and other economic models; no studies with human participants or animals were performed by any of the authors.

\section{Transition Probabilities}

Short- and long-term efficacy, relapse, and switching rates applied in the current model were obtained from published clinical trials and other health economic studies (Table 1). Short-term response rates were estimated on the basis of those reported in the RA-BEAM trial [18]. Patients in the MTX monotherapy treatment group switched to biologic therapy at month 6 , and no efficacy data were evaluated thereafter for MTX monotherapy. We therefore assumed no additional benefits in achieving remission after 6 months for MTX monotherapy, but applied the same linear change from high to low disease activity.

Patients who achieved remission during the initial 12 months of the treatment either maintained remission or relapsed into a low disease activity state over time. Based on relapse rates observed in the initial 3-month period after remission, relapse rates of $13 \%$ and $7 \%$ were applied for MTX monotherapy and biologic therapies, respectively, for each 3-month cycle in the current model. Patients who did not achieve remission after the initial year of treatment never achieved remission unless their treatment was changed.

Long-term efficacy considers the impact of treatment after the first 12 months until death. Long-term data reporting sustained efficacy of originator biologic and biosimilar treatments are limited. For this model, we applied

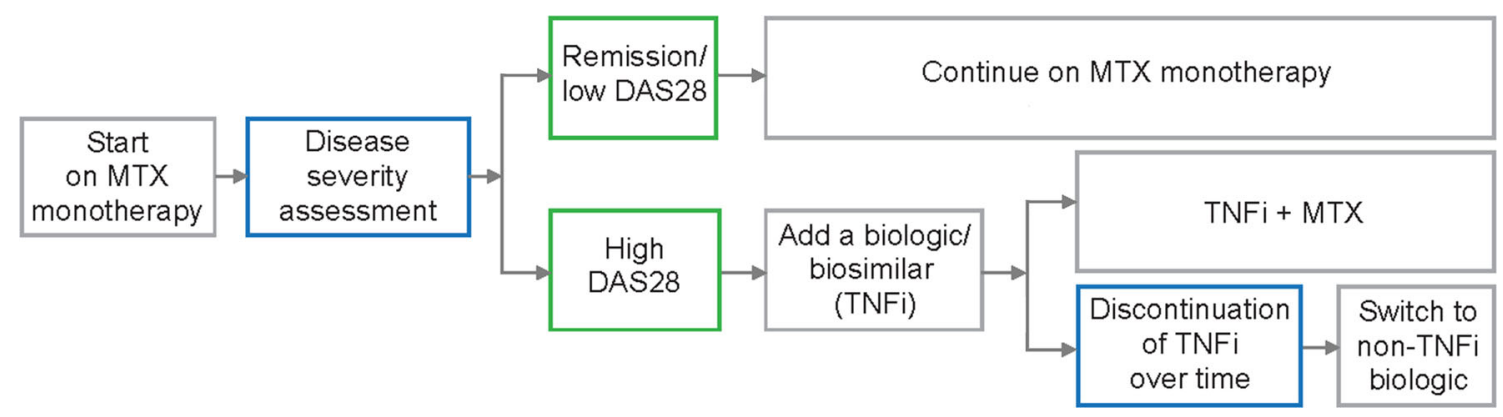

Fig. 1 Treatment pathways followed in the current model 
Table 1 Model inputs for clinical efficacy, relapse, and switching by treatment

\begin{tabular}{lllll}
\hline Short-term efficacy & & & \\
\hline $\begin{array}{l}\text { Time } \\
\text { (months) }\end{array}$ & Disease activity state & Patients (\%) & TNFi & Non-TNFi \\
\cline { 2 - 5 } 3 & MTX & 4 & 19 & 24 \\
& Remission & 10 & 16 & 20 \\
6 & Low disease activity & 6 & 32 & 34 \\
9 & Remission & 11 & 16 & 18 \\
& Low disease activity & 6 & 36 & 37 \\
12 & Remission & 11 & 13 & 17 \\
& Low disease activity & 6 & 39 & 40 \\
& Remission & 11 & 9 & 16
\end{tabular}

\begin{tabular}{|c|c|c|c|c|}
\hline \multicolumn{5}{|l|}{ Relapse } \\
\hline \multirow[t]{2}{*}{ Transition } & \multicolumn{4}{|c|}{ Transition probability per cycle } \\
\hline & $\overline{\text { MTX }}$ & TNFi & & Non-TNFi \\
\hline Remission to low disease activity & 0.13 & 0.7 & & 0.7 \\
\hline \multicolumn{5}{|l|}{ Long-term efficacy } \\
\hline \multirow[t]{2}{*}{ Transition } & \multicolumn{4}{|c|}{ Transition probability per cycle } \\
\hline & MTX & TNFi & & Non-TNFi \\
\hline Low to high disease activity & 0.05 & 0 & & 0 \\
\hline High to high disease activity & 1 & 1 & & 1 \\
\hline \multirow{2}{*}{$\begin{array}{l}\text { Time of treatment } \\
\text { initiation/switch (years) }\end{array}$} & \multicolumn{4}{|l|}{ Patients (\%) } \\
\hline & \multicolumn{2}{|l|}{$\overline{\text { MTX } \rightarrow \text { TNFi }}$} & \multicolumn{2}{|c|}{ TNFi $\rightarrow$ non-TNFi } \\
\hline 1 & 10.9 & & 14.6 & \\
\hline 2 & 10.9 & & 22.2 & \\
\hline 3 & 10.9 & & 11.5 & \\
\hline 4 & 10.9 & & 7.2 & \\
\hline 5 & 10.9 & & 3.5 & \\
\hline 6 & 0 & & 2.1 & \\
\hline 7 & 0 & & 1.0 & \\
\hline $8+$ & 0 & & 1.0 & \\
\hline
\end{tabular}

$M T X$ methotrexate, $T N F i$ tumor necrosis factor inhibitor

assumptions similar to those developed for the Birmingham Rheumatoid Arthritis Model (BRAM) [19], a lifetime model comparing several biologics to ongoing biologic/csDMARD therapy that failed to provide adequate disease control in patients with active RA. The Health 
Assessment Questionnaire (HAQ) was used to evaluate clinical effectiveness in BRAM based on two assumptions: first, patients who received biologic therapy maintained the same HAQ score over time unless they changed treatment (i.e., discontinued or switched); and second, patients who received csDMARD therapy had an annual reduction in HAQ score of 0.125 . Similarly, for the current model, biologic- or biosimilar-treated patients remained in the same disease activity state over time and MTXtreated patients with low disease activity had a $5 \%$ probability of relapse to a high disease activity state.

\section{Treatment Switch}

The rate of patients' switching from MTX monotherapy to combination MTX-originator biologic or combination MTX-biosimilar TNFi therapy was based on the median duration of csDMARD (leflunomide) therapy from BRAM [19] (Table 1). After a median duration of 6 years, it was assumed that no patients receiving MTX monotherapy switched to combination MTX-originator biologic or biosimilar TNFi therapy. The switching rate from TNFi to nonTNFi therapy was obtained from the Belgian expanded-access program cohort, in which infliximab continuation rates were evaluated over a 7-year period [20]. The switch rate at year 8 was applied for the remaining years, and patients receiving originator biologic non-TNFis were assumed to remain on the same therapy until death.

\section{Mortality}

At every cycle of the model, patients could die from natural causes. The model applied a hazard ratio of 1.29 for mortality to standard life tables for all patients, independent of disease activity state, to reflect the elevated risk of death in the RA population compared with the general population [21].

\section{Costs and Utilities}

The costs for the model were categorized as treatment costs, direct medical costs, direct non-medical costs, and indirect costs, related to
Table 2 Summary of annual costs for RA by disease severity, duration, and cost category [22]

\begin{tabular}{|c|c|c|c|c|}
\hline \multirow{2}{*}{$\begin{array}{l}\text { Disease } \\
\text { severity }\end{array}$} & \multirow{2}{*}{$\begin{array}{l}\text { Disease } \\
\text { duration } \\
\text { (years) }\end{array}$} & \multicolumn{3}{|c|}{ Annual cost $(\mathfrak{E})$} \\
\hline & & $\begin{array}{l}\text { Direct } \\
\text { medical }\end{array}$ & $\begin{array}{l}\text { Direct } \\
\text { non- } \\
\text { medical }\end{array}$ & Indirect \\
\hline \multirow{2}{*}{$\begin{array}{l}\text { Remission/ } \\
\text { mild }\end{array}$} & $6-10$ & 1630 & 1291 & 1639 \\
\hline & $>10$ & 2055 & 2224 & 4960 \\
\hline \multirow[t]{2}{*}{ Severe } & $6-10$ & 4678 & 4437 & 3875 \\
\hline & $>10$ & 7137 & 1523 & 6409 \\
\hline
\end{tabular}

$R A$ rheumatoid arthritis

work productivity. All costs (except treatment costs) were obtained from the BRASS study, an investigation of associations between disease activity, disease duration, and patient costs based on survey data from 4200 patients with RA across 10 European countries (Table 2) [22]. Remission and mild disease activity in the BRASS study corresponded to remission and low disease activity in our model, whereas severe disease activity (BRASS study) corresponded to high disease activity. Costs for $6-10$ years and $>10$ years of RA in the BRASS study were used for the first 10 years and $>10$ years, respectively, in the current model, and were adjusted to the 2017 UK $£$. All patients were assumed to be in the workforce until retirement age (i.e., men, 65.1 years; women, 63.6 years [23]).

Total treatment costs were estimated on the basis of dosing for patients weighing $70 \mathrm{~kg}$ and were halved for patients in remission (Table 3). The cost of originator biologic TNFis corresponded to the UK National Health Service (NHS) list price of infliximab, whereas the cost of biosimilar TNFis was derived from a single local contractual agreement [24]. Originator biologic non-TNFi costs were calculated from the weighted average NHS list prices for rituximab (85\%), abatacept (5\%), and tocilizumab (10\%) used in a UK biologic switching study [23] (a 50\% discount was assumed for the NHS list price of rituximab). Administration costs for the originator biologic TNFis, and the originator biologic non-TNFis abatacept and rituximab, were obtained from BRAM [19]; these costs for 
Table 3 Summary of treatment costs applied in the current model

\begin{tabular}{|c|c|c|c|}
\hline \multirow[t]{2}{*}{ Cost/dosing } & \multicolumn{3}{|c|}{ Treatment } \\
\hline & MTX & TNFi & $\begin{array}{l}\text { Originator } \\
\text { biologic } \\
\text { non-TNFi }\end{array}$ \\
\hline $\begin{array}{l}\text { Cost per unit } \\
(£)\end{array}$ & $\begin{array}{c}£ 0.117 \\
\text { per } \\
15 \text {-mg } \\
\text { tablet }\end{array}$ & $\begin{array}{l}\text { Originator } \\
\text { biologic: } \\
£ 419.67 \\
\text { per } \\
100 \text {-mg } \\
\text { vial } \\
\text { Biosimilar: } \\
£ 210 \text { per } \\
100 \text {-mg } \\
\text { vial }\end{array}$ & $\begin{array}{c}£ 719.15 \text { per } \\
\text { quarter }\end{array}$ \\
\hline Dosing & $\begin{array}{l}6 \text { tablets } \\
\text { per } \\
\text { week, } \\
\text { every } \\
\text { week }\end{array}$ & $\begin{array}{l}3 \text { vials per } \\
\text { dose } \\
6 \text { doses per } \\
\text { year }\end{array}$ & $\begin{array}{l}\text { Rituximab: } 4 \\
\text { vials per } \\
\text { dose; } 1 \\
\text { dose, every } \\
8.7 \text { months } \\
\text { Abatacept: } \\
750 \mathrm{mg} \text {, } \\
\text { every } \\
4 \text { weeks } \\
\text { Tocilizumab: } \\
8 \text { mg per kg, } \\
\text { every } \\
4 \text { weeks }\end{array}$ \\
\hline $\begin{array}{l}\text { Administration } \\
\text { cost }(£)\end{array}$ & - & $£ 212.75$ & $£ 153.27$ \\
\hline
\end{tabular}

$M T X$ methotrexate, TNFi tumor necrosis factor inhibitor

tocilizumab (not included in BRAM) were assumed to be the same as for abatacept.

To obtain utilities, DAS28 was first converted to HAQ scores as previously performed for an analysis of the relationship between disease activity and physical function [25]. The HAQ scores were subsequently transformed into utilities based on a simulation model developed to analyze the cost-effectiveness of new RA treatments in the UK (Table 4) [26].
Table 4 Utilities by disease activity state

\begin{tabular}{llll}
\hline $\begin{array}{l}\text { Disease activity } \\
\text { state }\end{array}$ & DAS28 & HAQ & $\begin{array}{l}\text { Utilities (SD) per } \\
\text { year }\end{array}$ \\
\hline Remission & $<2.6$ & 0.15 & $0.746(0.140)$ \\
Low & $<3.2$ & 0.5 & $0.746(0.140)$ \\
High & $\geq 3.2$ & 1.3 & $0.469(0.268)$ \\
\hline
\end{tabular}

DAS28 disease activity score in 28 joints, $H A Q$ Health Assessment Questionnaire, $S D$ standard deviation

\section{Analyses}

\section{Base-Case Analyses}

Total costs (i.e., the sum of treatment, direct medical and non-medical, and indirect costs) and utilities were compared between two main treatment strategies: (1) addition of an originator biologic TNFi to MTX monotherapy at 12 months (i.e., standard intervention); and (2) addition of an originator biologic or biosimilar TNFi to MTX monotherapy at 6 months (i.e., early intervention). These strategies were further examined by calculating the incremental cost-effectiveness ratio [ICER; $£$ per qualityadjusted life-year (QALY)] from total costs and utilities at the end of a patient's lifetime. Costs and other economic parameters were analyzed with a discount of $3 \%$.

\section{Sensitivity Analysis}

Probabilistic sensitivity analysis was performed to explore the effects of variability in key input parameters on cost-effectiveness outcomes as follows: (1) variance reported in the published literature were used when available; (2) other clinical trials or time of evaluation were referenced for efficacy; and (3) costs were increased or decreased by $10 \%$ from the current cost assuming gamma distribution.

\section{RESULTS}

\section{Base-Case Analyses}

Early addition of an originator biologic TNFi after 6 months of MTX monotherapy in patients with RA who had an inadequate 
Table 5 Lifetime costs per patient for patients switching to combination MTX-originator biologic TNFi therapy at 12 months (standard) versus combination MTX-originator biologic TNFi or combination MTX-biosimilar TNFi therapy at 6 months (early)

\begin{tabular}{|c|c|c|c|c|c|c|}
\hline \multirow[t]{3}{*}{ Cost } & \multicolumn{6}{|c|}{ Lifetime $\operatorname{cost}^{\mathrm{a}}$ per patient $(\mathfrak{E})$} \\
\hline & \multicolumn{3}{|c|}{$\begin{array}{l}\text { Switch from MTX monotherapy to combination } \\
\text { MTX + originator TNFi therapy }\end{array}$} & \multicolumn{3}{|c|}{$\begin{array}{l}\text { Switch from MTX monotherapy to combination } \\
\text { MTX + originator/biosimilar TNFi therapy }\end{array}$} \\
\hline & $\begin{array}{l}\text { Standard } \\
\text { intervention: } \\
\text { originator biologic } \\
\text { at } 12 \text { months }\end{array}$ & $\begin{array}{l}\text { Early } \\
\text { intervention: } \\
\text { originator } \\
\text { biologic at } \\
6 \text { months }\end{array}$ & Difference & $\begin{array}{l}\text { Standard } \\
\text { intervention: } \\
\text { originator biologic } \\
\text { at } 12 \text { months }\end{array}$ & $\begin{array}{l}\text { Early } \\
\text { intervention: } \\
\text { biosimilar at } \\
6 \text { months }\end{array}$ & Difference \\
\hline Treatment & 37,340 & 42,041 & 4701 & 24,021 & 27,099 & 3078 \\
\hline Direct & 40,942 & 38,571 & -2371 & 40,942 & 38,571 & -2371 \\
\hline Indirect & 14,853 & 14,216 & -637 & 14,853 & 14,216 & -637 \\
\hline Total $^{\mathrm{b}}$ & 93,135 & 94,827 & 1692 & 79,816 & 79,886 & 70 \\
\hline
\end{tabular}

MTX methotrexate, TNFi tumor necrosis factor inhibitor

${ }^{a}$ Including 3\% discount

b Totals may not sum to exactly $100 \%$ due to rounding of costs

response to MTX monotherapy increased treatment cost by $£ 4701$ per patient, but decreased lifetime direct and indirect costs by $£ 3008$ per patient. Overall early intervention approach thus resulted in a net increase of $£ 1692$ per patient compared to standard intervention with an originator biologic TNFi at 12 months (Table 5). The model assumed that the efficacy of originator biologic and biosimilar TNFis was the same, while reflecting the lower cost of biosimilars. Therefore, addition of a biosimilar TNFi after 6 months of MTX monotherapy resulted in the same changes in lifetime direct and indirect costs plus utilities as the early biologic intervention, but less of an increase in treatment cost $(£ 3078)$. Total costs were increased by $£ 70$ per patient when patients were switched from MTX monotherapy to combination therapy with a biosimilar TNFi at 6 months rather than combination therapy with an originator biologic TNFi at 12 months.

Utilities increased by 0.10 QALYs in patients who received early treatment with either an originator biologic or a biosimilar TNFi, from 5.4 QALYs for standard intervention to 5.5 QALYs for early intervention. Initiating treatment with an originator biologic TNFi at 6 months compared with 12 months was shown to be cost-effective at a threshold of $£ 30,000$ / QALY, with ICERs of $£ 17,335 /$ QALY and $£ 713$ / QALY with an originator biologic and biosimilar, respectively.

\section{Sensitivity Analyses}

When the robustness of the base-case results was tested by conducting probabilistic sensitivity analyses, the probability that early intervention with an originator biologic TNFi was cost-effective at a threshold of $£ 30,000 / \mathrm{QALY}$ was $82 \%$ with variance in model input parameters. Similarly, the probability that early intervention with a biosimilar TNFi was cost-effective was $83 \%$.

\section{DISCUSSION}

Despite the documented benefits of early control of inflammatory processes and the safety and efficacy of biologics such as TNFis, initiation of biologic treatment is frequently delayed, at least in part because of concerns about the cost of treatment. Our model was developed to understand the potential health-economic implications of early intervention with originator biologic or 
biosimilar TNFis in patients with RA who have an inadequate response to MTX. To our knowledge, this is the first model to compare the cost-effectiveness of standard versus early intervention with biologics.

On the basis of the findings from this model, early initiation of originator biologic or biosimilar TNFis in patients with RA who have an inadequate response to MTX is cost-effective compared with biologic initiation after unsuccessful treatment with MTX alone for 12 months. Earlier addition of an originator biologic/biosimilar TNFi to csDMARD therapy was associated with reduced direct (excluding treatment) and indirect costs and improved utilities. The cost savings partially offset the higher treatment costs incurred with early biologic TNFi initiation, preserving the costeffectiveness of this approach. Moreover, reductions in direct and indirect costs were comparable to increases in treatment costs for biosimilars when these agents were initiated at 6 months, improving upon the cost-effectiveness profile of early biologic use.

The findings from this analysis help enhance our understanding of the potential economic impact of early treatment with originator biologics and biosimilars. However, several limitations should be considered when interpreting the results. Because published long-term efficacy data on biologics are limited, assumptions regarding long-term efficacy were made on the basis of previously published models. Treatment switching and discontinuation were options available only to patients with high disease activity levels, which may not reflect real-world clinical decision-making or practice patterns. In addition, a simplified care paradigm was implemented for the model (i.e., the same treatment sequence was assumed for all patients). This paradigm does not reflect realworld treatment pathways in RA, which are complex, dependent on multiple factors, and highly individualized. The efficacy input for the model was based on efficacy data from a clinical trial, which may not reflect real-world outcomes. Finally, the biosimilar landscape is rapidly evolving. Costs of biosimilars and originator products will likely continue to change before stabilizing in the different countries where they are available. These cost fluctuations should be kept in mind when considering the findings from the current analysis, which is based on the most recent drug costs.

\section{CONCLUSION}

Our findings warrant additional research that further explores the cost-effectiveness of earlier introduction of originator biologic/biosimilar therapy in RA. In future models, alternative treatment strategies may also be examined, including a treat-to-target approach that entails modifying treatment based on achievement of objective, such as clinically meaningful target responses rather than clinical symptoms. Nevertheless, this analysis represents an important first step and suggests the cost-effectiveness of early biologic/biosimilar intervention with very low ICERs.

\section{ACKNOWLEDGEMENTS}

The authors would like to thank Dr Claire Bombardier MD, FRCP, of the Department of Medicine and Institute of Health Policy, Management and Evaluation, at the University of Toronto, for her valuable contributions to this work.

Funding. This work was funded by Pfizer Inc. The journal's article-processing charges and Open Access fee were also funded by Pfizer Inc. All authors had full access to all of the data in this study and take complete responsibility for the integrity of the data and accuracy of the data analysis.

Medical Writing and Editorial Assistance. Medical writing and editorial support was provided by Donna McGuire of Engage Scientific Solutions and was funded by Pfizer Inc.

Authorship. All named authors meet the International Committee of Medical Journal Editors (ICMJE) criteria for authorship for this article, take responsibility for the integrity of the work as a whole, and have given their approval for this version to be published. 
Disclosures. Dipen Patel is an employee of Pharmerit International, which received funding from Pfizer Inc. for analysis design, execution, analysis, and manuscript development. Dipen Patel was an employee of Pfizer Inc. at the time of this manuscript's development. Jyoti Aggarwal is an employee of Pharmerit International, which received funding from Pfizer Inc. for analysis design, execution, analysis, and manuscript development. Sang Hee Park is an employee of Pharmerit International, which received funding from Pfizer Inc. for analysis design, execution, analysis, and manuscript development. Ahmed Shelbaya is an employee of and owns stock or options in Pfizer Inc. Raymond Cheung is an employee of and owns stock or options in Pfizer Inc. Javier Coindreau was an employee of Pfizer Inc. at the time of this manuscript's development and is now an employee of Gilead Sciences.

Compliance with Ethics Guidelines. The model used in this analysis was based on previously conducted studies and other economic models; no studies with human participants or animals were performed by any of the authors.

Data Availability. The datasets generated during and/or analyzed during the current study are available from the corresponding author on reasonable request.

Open Access. This article is distributed under the terms of the Creative Commons Attribution-NonCommercial 4.0 International License (http://creativecommons.org/licenses/ by-nc/4.0/), which permits any noncommercial use, distribution, and reproduction in any medium, provided you give appropriate credit to the original author(s) and the source, provide a link to the Creative Commons license, and indicate if changes were made.

\section{REFERENCES}

1. Smolen JS, Aletaha D, Barton A, et al. Rheumatoid arthritis. Nat Rev Dis Primers. 2018;4:18001.
2. World Health Organization. Chronic rheumatic conditions. 2019. https://www.who.int/chp/topics/ rheumatic/en/. Accessed Feb 27, 2019.

3. Chen C-I, Wang L, Wei W, Yuce H, Phillips K. Burden of rheumatoid arthritis among US Medicare population: co-morbidities, health-care resource utilization and costs. Rheumatol Adv Pract. 2018;2:rky005-rky05.

4. Taylor PC, Moore A, Vasilescu R, Alvir J, Tarallo M. A structured literature review of the burden of illness and unmet needs in patients with rheumatoid arthritis: a current perspective. Rheumatol Int. 2016;36:685-95.

5. Lundkvist J, Kastang F, Kobelt G. The burden of rheumatoid arthritis and access to treatment: health burden and costs. Eur J Health Econ. 2008;8(Suppl 2):S49-60.

6. Emery P, Sebba A, Huizinga TW. Biologic and oral disease-modifying antirheumatic drug monotherapy in rheumatoid arthritis. Ann Rheum Dis. 2013;72:1897-904.

7. Al Maini M, Adelowo F, Al Saleh J, et al. The global challenges and opportunities in the practice of rheumatology: white paper by the World Forum on Rheumatic and Musculoskeletal Diseases. Clin Rheumatol. 2015;34:819-29.

8. European Medicines Agency. Guideline on similar biological medicinal products. CHMP/437/04 Rev. 1. 2014. http://www.ema.europa.eu/docs/en_GB/ document_library/Scientific_guideline/2014/10/WC 500176768.pdf. Accessed June 25, 2018.

9. United States Food and Drug Administration. Considerations in demonstrating interchangeability with a reference product: guidance for industry. 2019. https://www.fda.gov/downloads/Drugs/Guidance ComplianceRegulatoryInformation/Guidances/ UCM537135.pdf. Accessed May 16, 2019.

10. World Health Organization, Expert Committee on Biological Standardization. Guidelines on evaluation of similar biotherapeutic products (SBPs). 2009. http://www.who.int/biologicals/areas/biologi cal_therapeutics/BIOTHERAPEUTICS_FOR_WEB_ 22APRIL2010.pdf. Accessed June 25, 2018.

11. Dorner T, Strand V, Cornes P, et al. The changing landscape of biosimilars in rheumatology. Ann Rheum Dis. 2016;75:974-82.

12. Keystone EC, Haraoui B, Guerette B, Mozaffarian N, Liu S, Kavanaugh A. Clinical, functional, and radiographic implications of time to treatment response in patients with early rheumatoid arthritis: a posthoc analysis of the PREMIER study. J Rheumatol. 2014;41:235-43. 
13. Aletaha D, Smolen J, Ward MM. Measuring function in rheumatoid arthritis: identifying reversible and irreversible components. Arthritis Rheum. 2006;54:2784-92.

14. Makinen H, Kautiainen H, Hannonen P, et al. Sustained remission and reduced radiographic progression with combination disease modifying antirheumatic drugs in early rheumatoid arthritis. J Rheumatol. 2007;34:316-21.

15. Rantalaiho V, Korpela M, Hannonen $\mathrm{P}$, et al. The good initial response to therapy with a combination of traditional disease-modifying antirheumatic drugs is sustained over time: the eleven-year results of the Finnish rheumatoid arthritis combination therapy trial. Arthritis Rheum. 2009;60:1222-31.

16. Monti S, Montecucco C, Bugatti S, Caporali R. Rheumatoid arthritis treatment: the earlier the better to prevent joint damage. RMD Open. 2015;1:e000057.

17. van der Velde G, Pham B, Machado M, et al. Costeffectiveness of biologic response modifiers compared to disease-modifying antirheumatic drugs for rheumatoid arthritis: a systematic review. Arthritis Care Res (Hoboken). 2011;63:65-78.

18. Taylor PC, Keystone EC, van der Heijde D, et al. Baricitinib versus placebo or adalimumab in rheumatoid arthritis. $\mathrm{N}$ Engl $\mathrm{J}$ Med. 2017;376:652-62.

19. Malottki K, Barton P, Tsourapas A, et al. Adalimumab, etanercept, infliximab, rituximab and abatacept for the treatment of rheumatoid arthritis after the failure of a tumour necrosis factor inhibitor: a systematic review and economic evaluation. Health Technol Assess. 2011;15:1-278.

20. Vander Cruyssen B, Durez P, Westhovens R, De Keyser F. Seven-year follow-up of infliximab therapy in rheumatoid arthritis patients with severe long-standing refractory disease: attrition rate and evolution of disease activity. Arthritis Res Ther. 2010;12:R77.

21. Zhang Y, Lu N, Peloquin C, et al. Improved survival in rheumatoid arthritis: a general population-based cohort study. Ann Rheum Dis. 2017;76:408-13.

22. Capron J, De Leonardis F, Fakhouri W, Burke T, Rose A, Jacob I. The impact of disease duration and disease activity on the cost of rheumatoid arthritis: results from Burden of Rheumatoid Arthritis Across Europe a Socioeconomic Survey (BRASS). Value Health. 2017;20:A532.

23. Department for Work \& Pensions. Economic labour market status of individuals aged 50 and over, trends over time: September 2017 (experimental). Data for 1950 to 2017. 2017. https://assets.publis hing.service.gov.uk/government/uploads/system/ uploads/attachment_data/file/642157/economiclabour-market-status-of-individuals-aged-50-andover-since-1950.pdf. Accessed May 29, 2018.

24. Muhammad R, Whyte L, Protheroe S, Bremner R, Haller W, Wong T. Comparison of efficacy and safety of biosimilar infliximab to originator infliximab in children with inflammatory bowel disease. 2016. https://www.ecco-ibd.eu/publications/congre ss-abstract-s/item/p382-comparison-of-efficacy-andsafety-of-biosimilar-infliximab-to-originator-inflixi mab-in-children-with-inflammatory-bowel-disease. html?highlight=WyJiaW9zaW1pbGFyliwiYmlvc21 taWxhcnMiLCJpbmZsaXhpbWFiliwiYmlvc2ltaWx hciBpbmZsaXhpbWFillo. Accessed May 29, 2018.

25. Aletaha D, Ward MM, Machold KP, Nell VP, Stamm $\mathrm{T}$, Smolen JS. Remission and active disease in rheumatoid arthritis: defining criteria for disease activity states. Arthritis Rheum. 2005;52:2625-36.

26. Kobelt G, Jonsson L, Lindgren P, Young A, Eberhardt K. Modeling the progression of rheumatoid arthritis: a two-country model to estimate costs and consequences of rheumatoid arthritis. Arthritis Rheum. 2002;46:2310-9. 